\title{
Array-based comparative genomic hybridization for genomic-wide screening of DNA copy number alterations in aggressive bone tumors
}

\author{
Masahiko Kanamori ${ }^{1,2 *}$, Akimi Sano ${ }^{2}$, Taketoshi Yasuda ${ }^{2}$, Takeshi Hori ${ }^{2}$ and Kayo Suzuki ${ }^{2}$
}

\begin{abstract}
Background: The genetic pathways of aggressive changes of bone tumors are still poorly understood. It is very important to analyze DNA copy number alterations (DCNAs), to identify the molecular events in the step of progression to the aggressive change of bone tissue.

Methods: Genome-wide array-based comparative genomic hybridization (array CGH) was used to investigate DCNAs of 14 samples from 13 aggressive bone tumors, such as giant cell tumors (GCTs) and osteosarcoma (OS), etc.

Results: Primary aggressive bone tumors had copy number gains of $17.8 \pm 12.7 \%$ in the genome, and losses of 17.3 $\pm 11.4 \%$ in 287 target clones (threshold for each DCNA: $\leqq 085,1.15 \leqq$ ). Genetic unstable cases, which were defined by the total DCNAs aberration $\geqq 30 \%$, were identified in 9 of 13 patients (3 of 7 GCTs and all malignant tumors). High-level amplification of TGFß2, CCND3, WI-6509, SHGC-5557, TCL1A, CREBBP, HIC1, THRA, AFM217YD10, LAMA3, RUNX1 and D22S543, were commonly observed in aggressive bone tumors. On the other hand, NRAS, D2S447, RAF1, ROBO1, MYB, MOS, FGFR2, HRAS, D13S319, D13S327, D18S552, YES1 and DCC, were commonly low. We compared genetic instability between a primary OS and its metastatic site in Case \#13. Metastatic lesion showed increased 9 DCNAs of remarkable change (m/p ratio $\geqq 1.3$ folds), compared to a primary lesion. D1S214, D1S1635, EXT1, AFM137XA11, 8 M16/SP6, CCND2, IGH, 282 M15/SP6, HIC1 and LAMA3, were overexpressed. We gave attention to HIC1 (17p13.3), which was common high amplification in this series.
\end{abstract}

Conclusion: Our results may provide several entry points for the identification of candidate genes associated with aggressive change of bone tumors. Especially, the locus 17p11-13 including HICl close to p53 was common high amplification in this series and review of the literature.

Keywords: Osteosarcoma, Giant cell tumor, Bone tumors, Microarray, Comparative genomic hybridization

\section{Background}

The development and progression of aggressive bone tumor is a multi-step process. The acquisition of chromosomal abnormalities in tumor cells and a series of genetic alterations occurring over the life-time of the tumor are one of the central events in malignant transformation or aggressive change. Multiple studies have identified the prevalence and clinical significance of a various genetic markers in primary bone tumors $[1,2]$. However, the genetic pathways of aggressive changes of bone tumors are

\footnotetext{
* Correspondence: kanamori@med.u-toyama.ac.jp

'Department of Human Science, University of Toyama, 2630 Sugitani, Toyama city, Toyama 930-0194, Japan

${ }^{2}$ Department of Orthopaedic Surgery, University of Toyama, 2630 Sugitani, Toyama city, Toyama 930-0194, Japan
}

\section{() BioMed Central}

still poorly understood. It is very important to analyze DNA copy number alterations (DCNAs), to identify the molecular events in the step of progression to the aggressive change of bone tissue.

Metaphase comparative genomic hybridization (metaphase CGH) enabled us to detect DCNAs on whole chromosomes [3,4]. But the resolution of metaphase CGH is approximately $2 \mathrm{Mb}$ for amplifications and $10-20 \mathrm{Mb}$ for deletions. Advances in mapping resolution using arraybased CGH (array CGH), have greatly improved resolving power in comparison to metaphase $\mathrm{CGH}$, and provide more details regarding both the complexity and exact location of genomic rearrangements leading to DCNAs $[5,6]$. Thereafter, array CGH technologies for identifying 
target molecules developed to permit for the identification of genes involved in tumors $[3,4]$.

In this study, we investigated DCNAs of human aggressive bone tumors using the technique of array CGH. The quantitative measurement of DCNAs across the genome may facilitate oncogene identification, and might also be used for tumor classification.

\section{Materials and methods}

\section{Tumor tissue specimens and DNA extraction}

Fourteen bone tumor samples were collected from 13 patients with aggressive bone tumors and frozen until use. Samples from 7 giant cell tumors (GCTs), 5 osteosarcoma (OS) and 1 chondrosarcoma, were obtained from the surgical- or biopsied specimens at the University Hospital of Toyama (Table 1). Patients consisted of 6 men and 7 women with an average age of 32.9 years old (range, 7-65 years). No cases had been received the chemotherapy before the sampling. This study protocol was approved by the Institutional Review Board for Human Use at the University Hospital of Toyama.

Tumor specimens were stored frozen at $-80^{\circ} \mathrm{C}$ until use. Genomic DNA was isolated from the tumor according to standard procedures using proteinase $\mathrm{K}$ digestion and phenol-chloroform extraction [7].

\section{Hybridization and analysis of array CGH}

Hybridization and analysis of array CGH were performed according to the manufacture's protocols (Vysis-Abbott Japan Inc., Tokyo, JAPAN). The array CGH consisted of 287 clones containing important tumor suppressor and oncogene loci. Each tumor DNA sample was labeled and hybridized to microarrays for CGH. One hundred nanogram of tumor DNA was labeled by random priming with fluorolink cy3-dUTP (Perkin-Elmer Life Sciences, Inc, Boston, MA, USA), and normal reference DNA was labeled in the same fashion with cy5-dUTP. Then, the tumor and control DNAs were mixed with Cot-1 DNA (Vysis-Abbott Japan Inc), precipitated, and re-suspended in microarray hybridization buffer containing $50 \%$ formamide. The hybridization solution was heated to $80^{\circ} \mathrm{C}$ for 10 min to denature the DNA, and then was incubated for $1 \mathrm{~h}$ at $37^{\circ} \mathrm{C}$. Hybridization was performed for $72 \mathrm{~h}$ in a moist chamber, followed by post-hybridization wash in $50 \%$ formamide $/ 2 \mathrm{xSSC}$ at $45^{\circ} \mathrm{C}$. Slides were mounted in phosphate buffer containing 4', 6-diamidino- 2-phenylindole (array DAPI solution). Fluorescence intensity images were obtained from the hybridized microarray slides using GenoSensor Reader System equipped with Array 300 Software (Vysis-Abbott Japan Inc.) according to the manufacture's instructions. The total intensity and the intensity ratio of the two dyes for each spot were automatically calculated $[7,8]$.

\section{Evaluation of array CGH}

The diagnostic cut-off level representing gains and losses of DCNAs was set to 1.15 (upper threshold) and 0.85 (lower threshold), respectively $[7,8]$. The $p$ value is the probability that the data value for an individual set of target spots is part of the normal distribution. All ratios were filtered by $p$ values, and only those samples with $p$

\section{Table 1 Clinicopathologic data on the samples in genomic array analysis}

\begin{tabular}{|c|c|c|c|c|c|c|}
\hline Cases & Age & Gender* & Diagnosis** & Follow-up & Recurrence ${ }^{* * * *}$ & Outcome $e^{* * * * *}$ \\
\hline 1 & 16 & $F$ & $\mathrm{GCT}$ & $9 y$ & none & NED \\
\hline 2 & 16 & $F$ & $\mathrm{GCT}$ & $12.5 y$ & 1 & NED \\
\hline 3 & 18 & $M$ & $\mathrm{GCT}$ & $11.2 y$ & 1 & NED \\
\hline 4 & 21 & $M$ & $\mathrm{GCT}$ & $11 y$ & none & NED \\
\hline 5 & 25 & M & $\mathrm{GCT}$ & $12.3 y$ & none & NED \\
\hline 6 & 41 & $\mathrm{~F}$ & $\mathrm{GCT}$ & $20.6 y$ & 2 & AWD \\
\hline 7 & 55 & $M$ & $\mathrm{GCT}$ & $16.2 y$ & 2 & AWD \\
\hline 8 & 47 & $\mathrm{~F}$ & chondrosarcoma & $20 y$ & none & NED \\
\hline 9 & 7 & $F$ & OS & $4 y$ & metastasis (+) & DOD \\
\hline 10 & 41 & $M$ & OS & $9 \mathrm{~m}$ & metastasis (+) & DOD \\
\hline 11 & 58 & $F$ & OS & $20 y$ & none & NED \\
\hline 12 & 65 & $\mathrm{~F}$ & OS & $6 \mathrm{~m}$ & metastasis (+) & DOD \\
\hline $13 a$ & 18 & $M$ & OS (primary) & $4 m$ & metastasis (+) & DOD \\
\hline $13 b$ & & & OS (metastasis) & & & \\
\hline
\end{tabular}

*Gender; F: female, M: male.

**Diagnosis; GCT: giant cell tumor, OS: osteosarcoma.

***Follow-up; m: month, y: year.

****Recurrence: The number means operation times due to the recurrences.

*****NED: no evidence of disease, AWD: alive with disease, DOD: dead of disease. 
values of 0.01 or less were displayed in the GenoSensor Reader System.

We defined the three grades by the genomic imbalances from the data of array $\mathrm{CGH}$; genetically stable group (genetic aberration $<5 \%$ ), intermediate group ( $5 \% \leqq$ genetic aberration $<30 \%$ ), genetically unstable group (genetic aberration $\geqq 30 \%$ ).

\section{Statistical analysis}

The results are expressed as the mean \pm SD. We used independent sample $t$-test for continuous variables and chi square test for categorical variables in comparison. A $p$ value less than 0.05 was considered significant. All statistics were calculated using StatMate III software (Atoms Co., Tokyo, Japan).

\section{Results}

\section{Overall array CGH results in aggressive bone tumors}

Figure 1 shows a representative case, and a microarray slide which was hybridized by array CGH technique. DCNAs of primary tumors showed $17.8 \pm 12.7 \%$ in gains, and $17.3 \pm 11.4 \%$ in losses of target 287 clones. The average of the proportion of total genetic instability reached the $38.6 \pm 22.8 \%$. Genetic unstable cases which were defined by the total DCNAs aberration $(\geqq 30 \%)$ were identified in 9 of 13 patients ( 3 of 7 GCTs and all malignant tumors). All malignant cases were genetically classified into the unstable group. We picked up major gene names, which showed many gain cases or loss cases. An overall array $\mathrm{CGH}$ results and gene names of common genetic instability are listed in Figure 2.

High-level amplification of TGF 32 (1q41), CCND3 (6p21), WI-6509 (11qtel), SHGC-5557 (12ptel), TCL1A (14q32.1), CREBBP (16q13.3), HIC1 (17p13.3), THRA (17q11.2), AFM217YD10 (17qtel), LAMA3 (18q11.2), RUNX1 (21q22.3) and D22S543 (22q11), was commonly observed in aggressive bone tumors. On the other hand, NRAS (1p13.2), D2S447 (2qtel), ROBO1 (3p12-13), RAF1 (3p25), MYB (6q22-23), MOS (8q11), FGFR2 (10q26), HRAS (11q11.5), D13S319 (13q14.2), D13S327 (13qtel), YES1 (18p11), D18S552 (18ptel) and DCC (18q21.3) were commonly low (Figure 2).

\section{Clinical relevance in GCT}

GCT is an aggressive bone tumor, but not malignant. Seven GCT series were divided into three groups: 3 cases were genetically unstable group, and 3 cases were stable group (Figure 3 ). One case (Case \#7) belongs to the intermediate group. Histologically, however, we could not find the difference in each GCT case. The
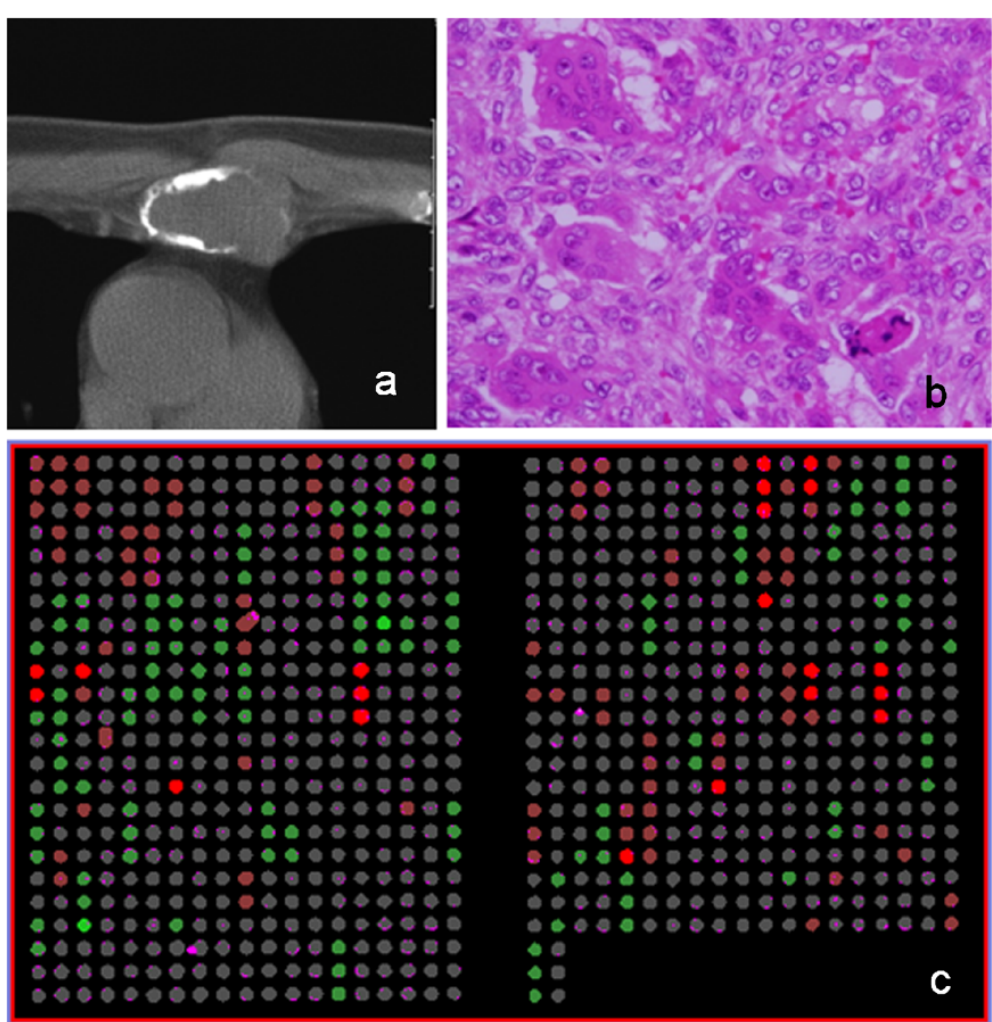

Figure 1 A representative case and an array CGH slide (Case \#7). a: Radiographs of GCT originated from sternum. b: Histological appearance showing GCT (H\&E x200). c: A study of microarray CGH. 


\begin{tabular}{|c|c|c|c|c|c|c|c|c|c|c|c|c|c|c|c|c|c|}
\hline \multicolumn{2}{|c|}{\begin{tabular}{|c|} 
Tumor/Cases \\
\end{tabular}} & \multicolumn{7}{|c|}{ Giant cell tumor } & \multirow{2}{*}{$\frac{\mathrm{CS}}{8}$} & \multicolumn{6}{|c|}{ osteosarcoma } & \multirow[b]{2}{*}{ gain cases } & \multirow[b]{2}{*}{ loss cases } \\
\hline \begin{tabular}{|l|l} 
Gene names \\
\end{tabular} & Location & 1 & 2 & 3 & 4 & 5 & 6 & 7 & & 9 & 10 & 11 & 12 & $13 \mathrm{a}$ & $13 \mathrm{~b}$ & & \\
\hline TGF $\beta 2$ & $1 \mathrm{q} 41$ & & & & & & & & & & & & & & & 7 & 0 \\
\hline CCND3 & $6 \mathrm{p} 21$ & & & & & & & & & & & & & & & 8 & 0 \\
\hline WI-6509 & 11qtel & & & & & & & & & & & & & & & 7 & 0 \\
\hline \begin{tabular}{|l|} 
SHGC-5557 \\
\end{tabular} & 12ptel & & & & & & & & & & & & & & & 8 & 0 \\
\hline \begin{tabular}{|l|} 
TCL1A \\
\end{tabular} & $14 \mathrm{q} 32.1$ & & & & & & & & & & & & & & & 8 & 0 \\
\hline CREBBP & $16 q 13.3$ & & & & & & & & & & & & & & & 7 & 0 \\
\hline HICl & $17 \mathrm{p} 13.3$ & & & & & & & & & & & & & & & 7 & 1 \\
\hline THRA & $17 \mathrm{q} 11.2$ & & & & & & & & & & & & & & & 8 & 0 \\
\hline AFM217YD10 & 17 qtel & & & & & & & & & & & & & & & 7 & 0 \\
\hline \begin{tabular}{|l|l|} 
LAMA3 \\
\end{tabular} & $18 \mathrm{q} 11.2$ & & & & & & & & & & & & & & & 7 & 1 \\
\hline RUNX1(AML1) & $21 \mathrm{q} 22.3$ & & & & & & & & & & & & & & & 7 & 0 \\
\hline D22S543 & $22 \mathrm{q} 11$ & & & & & & & & & & & & & & & 7 & 1 \\
\hline NRAS & $1 \mathrm{p} 13.2$ & & & & & & & & & & & & & & & 1 & 10 \\
\hline D2S447 & 2 qtel & & & & & & & & & & & & & & & 0 & 9 \\
\hline RAF1 & $3 \mathrm{p} 25$ & & & & & & & & & & & & & & & 0 & 7 \\
\hline D3S1274, ROBO1 & $3 \mathrm{p} 12-13$ & & & & & & & & & & & & & & & 0 & 8 \\
\hline MYB & $6 \mathrm{q} 22-23$ & & & & & & & & & & & & & & & 0 & 7 \\
\hline MOS & $8 \mathrm{q} 11$ & & & & & & & & & & & & & & & 0 & 7 \\
\hline FGFR2 & $10 \mathrm{q} 26$ & & & & & & & & & & & & & & & 0 & 9 \\
\hline HRAS & $11 \mathrm{q} 15.5$ & & & & & & & & & & & & & & & 2 & 7 \\
\hline D13S319 & $13 \mathrm{q} 14.2$ & & & & & & & & & & & & & & & 0 & 8 \\
\hline D13S327 & $13 \mathrm{qtel}$ & & & & & & & & & & & & & & & 0 & 7 \\
\hline D185552 & 18ptel & & & & & & & & & & & & & & & 0 & 8 \\
\hline YES1 & $18 \mathrm{p} 11$ & & & & & & & & & & & & & & & 0 & 7 \\
\hline DCC & $18 \mathrm{q} 21.3$ & & & & & & & & & & & & & & & 0 & 7 \\
\hline \multicolumn{2}{|c|}{\begin{tabular}{|l|} 
Genetic gain $(\%)^{*}$ \\
\end{tabular}} & 0.3 & 27.5 & 21.6 & 25.8 & 1.4 & 0.0 & 0.0 & 25.4 & 34.5 & 23.7 & 17.1 & 31.0 & 22.6 & 30.7 & & \\
\hline \multirow{2}{*}{\multicolumn{2}{|c|}{$\begin{array}{c}\text { Genetic loss }(\%)^{*} \\
\text { Total instability(\%) }\end{array}$}} & 1.4 & 21.6 & 16.0 & 26.8 & 2.8 & 0.0 & 18.1 & 12.5 & 30.0 & 18.1 & 19.9 & 39.4 & 17.8 & 26.1 & & \\
\hline & & 1.7 & 49.1 & \begin{tabular}{|l|l|}
37.6 \\
\end{tabular} & 52.6 & 4.2 & 0.0 & 18.1 & 37.9 & 64.5 & \begin{tabular}{|l|l|}
41.8 \\
\end{tabular} & 37.0 & \begin{tabular}{|l|}
70.4 \\
\end{tabular} & 40.4 & 56.8 & & \\
\hline \multicolumn{18}{|c|}{$\begin{array}{l}\text { Green and red squares represent decreases (Tumor DNA/Normal DNA ratio } \leqq 0.85 \text { ) and increases (Tumor DNA/Normal DNA ratio } \geqq 1.15 \text { ) of DCNAs, respect } \\
{ }^{*} \text { Genetic gain/loss (\%) are caliculated as a ratio of increase or decrease of DCNAs based on the data of } 287 \text { clones. } \\
\text { CS: chondrosarcoma, Case \#13a: primary tumor, \#13b: metastatic tumor }\end{array}$} \\
\hline Figure 2 Summa & ry of DCN & As & & & & [GH & & & & & & & & & & & \\
\hline
\end{tabular}

mean clinical follow-up time of these GCT cases was 11.8 years. Tumor recurrence was observed in all cases of genetically unstable group. On the other hand, the recurrence rate of stable group was low (33.3\%). However, there was no significance between two groups (chi- square test; $p=0.083$ ), because the sample size was small.

As many GCTs have some telomeric associations, we have given an attention to these areas. In analyzed 73 clones of telomeric area, losses of D2S447 (2qtel), and
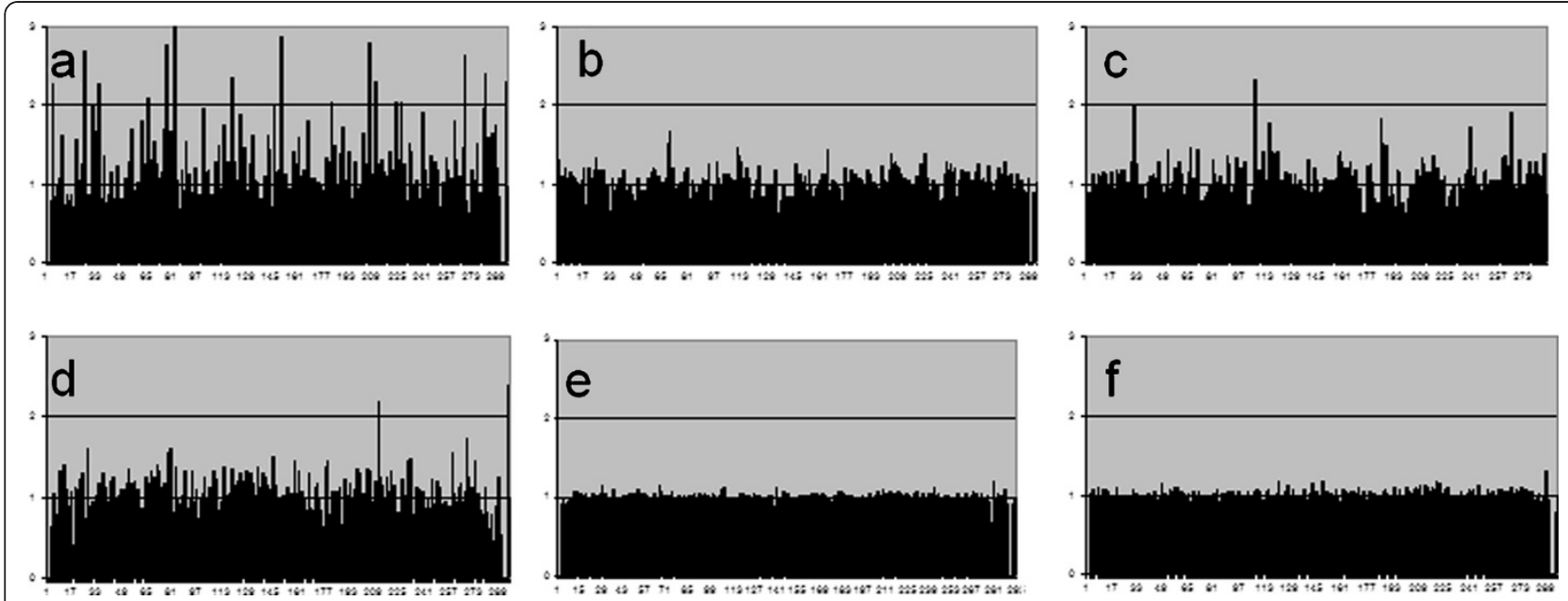

Figure 3 Representative genetic unstable group (a-d) and stable group (e, f) in a study of microarray CGH. a: Case \#9 (OS), b: Case \#10 $(\mathrm{OS})$, c: Case \#12 (OS), d: Case 4 (GCT), e: Case \#2 (GCT), f: Case \#5 (GCT). 
gain of WI-6509 (11qtel) and D19S238E (19qtel) were mainly observed.

\section{Primary vs. Metastatic OS}

We compared the genetic instability of both primary OS and a metastatic lymph node in Case \#13. Briefly, 18-year-old man presented with the left shoulder mass. Radiographs revealed an osteosclerotic lesion of the proximal humerus (Figure 4a). A chest radiogram and CT scans showed multiple lung metastases. A small nodule was palpable in the axillary region. We biopsied bone tumor and removed a local swelling lymph node. Histologic examination of the both samples showed osteoblastic OS (Figure $4 \mathrm{~b}$ ). Chromosomal analysis by G-band showed 77-82 chromosomes with various complicated translocation from the primary tumor.

In this case, array $\mathrm{CGH}$ resulted in $22.6 \%$ gain of DCNAs and $17.8 \%$ loss of primary tumor (genetic total instability; 40.4\%). Chromosomal instabilities of primary tumor detected by array CGH, are figured out (Figure 4c). However, a metastatic lymph node showed the gain of $30.7 \%$, and the loss of $26.1 \%$ of DCNAs (genetic total instability; 56.8\%). Genetic aberrations of a metastatic lesion were clearly increased (Figure 4d). We picked up detected
DCNAs presenting with remarkable significant gains $(\geqq 1.30)$ or losses $(\leqq 0.85)$ in a metastatic sample compared to a primary sample (m/p ratio), and listed in Table 2 . Thirty-one DCNAs of 287 clones were gained. Of these, 12 DCNAs also showed high level amplification in the primary site.

It is important to assess the change of DCNAs between a metastatic tumor and a primary tumor. Nine DCNAs ( $\mathrm{m} / \mathrm{p}$ ratio $\geqq 1.30$ folds) showed remarkable enhancement, compared to a primary lesion; D1S1635 (1p36.22), D1S214 (1p36.31), EXT1 (8q24.11-q24), AFM137XA11 (9p11.2), CCND2 (12p13), 8M16SP6 (12ptel), IGH (14qtel), HIC1 (17p13.3) and LAMA3 (18q11.2), 282 M15/SP6 (17ptel). On the other hand, loss of DCNAs $(\leqq 0.85)$ in a metastatic sample, was only $L L G L 1(\mathrm{~m} / \mathrm{p}$ ratio $=0.81)$ and $F L I$ (TOP3A) $(\mathrm{m} / \mathrm{p}$ ratio $=0.85)$. Both of these genes are encoded on the location of 17p11.2-17p12. These DCNAs showing remarkable enhancement or decreasing, may provide several entry points for the identification of candidate genes associated with metastatic ability.

\section{Discussion}

Our present analysis indicated to 25 genes showing genetic instability, as target genes of aggressive bone tumors
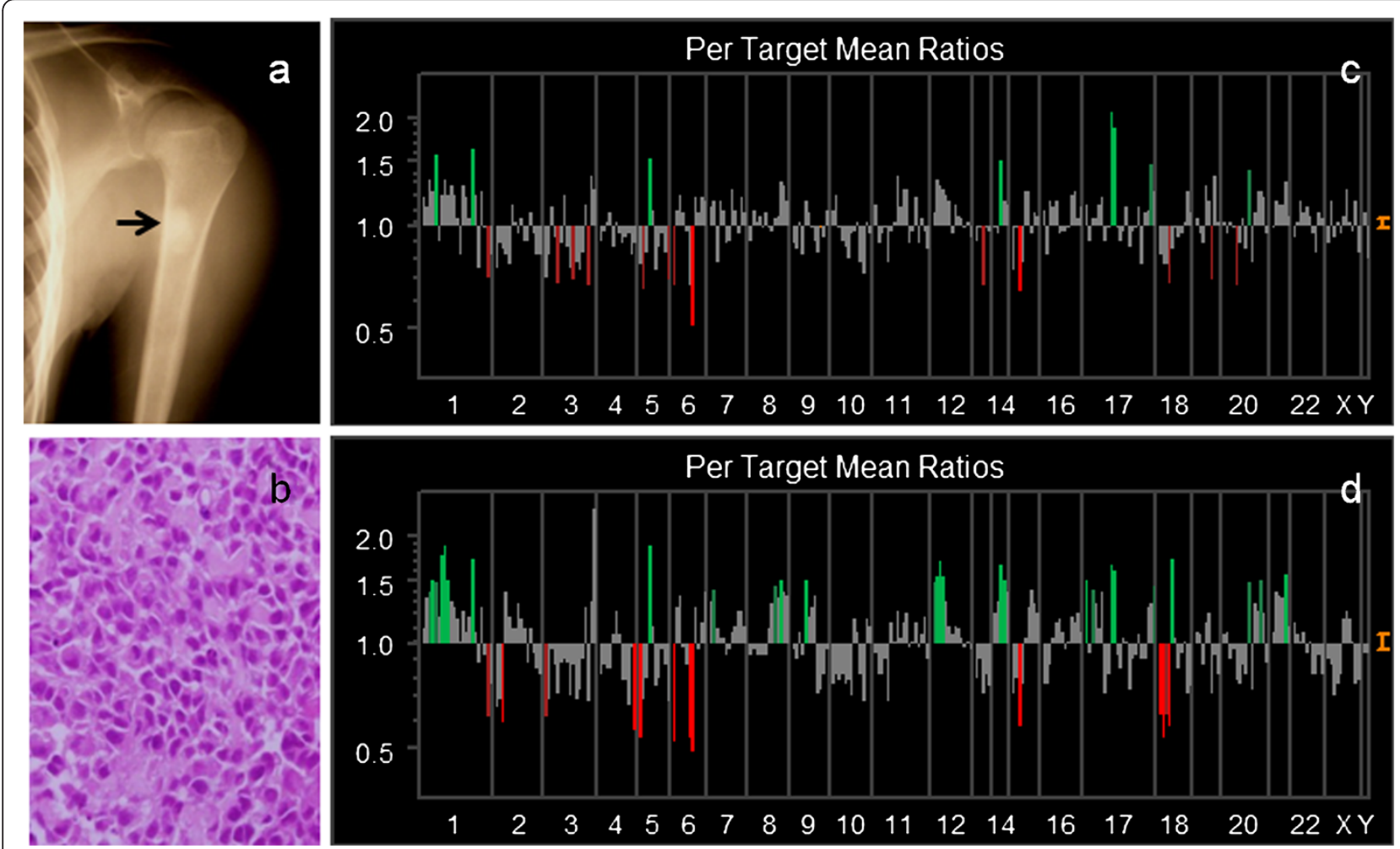

Figure 4 Genetic instability analyzed by array CGH in Case \#13. Primary bone tumors showed the genetic instability of 26 DCNAs of 287 clones (c), whereas a metastatic lymph node showed 57 DCNAs in 287 clones (d). The genetic aberration of metastatic lymph node is relatively high

compared with a primary bone tumor. a: A radiogram of humerus showing the osteosclerotic change by the osteosarcoma. $\mathbf{b}$ : Histological appearance showing atypical cells with osteoid formation. c: A study of microarray CGH (primary tumor). d: A study of microarray CGH (metastatic tumor). 
Table 2 Genetic instability between primary and metastatic tumor at Case \#13

\begin{tabular}{|c|c|c|c|c|c|}
\hline & location & Gene name & metastasis ( $\geqq 1.30)$ & primary tumor & $\mathrm{m} / \mathrm{p}$ ratio \\
\hline \multirow[t]{6}{*}{$1 p$} & $1 p 36$ & CDC2L1(p58) & 1.39 & 1.33 & 1.05 \\
\hline & 1p36.33 & PPKCZ & 1.52 & 1.24 & 1.23 \\
\hline & 1p36.33 & TP73 & 1.48 & 1.58 & 0.94 \\
\hline & 1p36.31 & D1S214 & 1.76 & 1.21 & $1.45^{*}$ \\
\hline & $1 p 36.22$ & D1S1635 & 1.88 & 1.33 & $1.41^{*}$ \\
\hline & $1 p 36.13$ & D1S199 & 1.51 & 1.22 & 1.24 \\
\hline $1 q$ & $1 \mathrm{q} 21$ & WI-5663 & 1.73 & 1.64 & 1.05 \\
\hline $5 p$ & $5 p 13$ & DAB2 & 1.87 & 1.55 & 1.21 \\
\hline \multirow[t]{4}{*}{$8 q$} & $8 q 24.11-q 24$ & EXT1 & 1.44 & 1.03 & $1.40^{*}$ \\
\hline & 8q24-qter & PTK2 & 1.51 & 1.31 & 1.15 \\
\hline & $8 q$ tel & SHGC-3110 & 1.40 & 1.29 & 1.09 \\
\hline & $8 q$ tel & U11829 & 1.35 & 1.16 & 1.16 \\
\hline $9 p$ & $9 p 11.2$ & AFM137XA11 & 1.52 & 1.16 & $1.31^{*}$ \\
\hline \multirow[t]{4}{*}{$12 p$} & $12 p$ tel & $8 \mathrm{M} 16 / \mathrm{SP} 6$ & 1.49 & 1.08 & $1.38^{*}$ \\
\hline & $12 p$ tel & SHGC-5557 & 1.52 & 1.34 & 1.13 \\
\hline & $12 \mathrm{p} 13$ & CCND2 & 1.71 & 1.29 & $1.33^{*}$ \\
\hline & $12 p 13.1-p 12$ & CDLN1B(p27) & 1.53 & 1.25 & 1.22 \\
\hline \multirow[t]{3}{*}{$14 q$} & $14 q 32.32$ & AKT1 & 1.68 & 1.51 & 1.11 \\
\hline & $14 q$ tel & IGH(D14S308) & 1.51 & 1.16 & $1.30^{*}$ \\
\hline & $14 q$ tel & IGH(SHGC-36156) & 1.39 & 1.14 & 1.22 \\
\hline \multirow[t]{5}{*}{$17 p$} & $17 p$ tel & 282 M15/SP6 & 1.52 & 1.14 & $1.33^{*}$ \\
\hline & $17 p 13.3$ & $\mathrm{HIC1}$ & 1.42 & 1.04 & $1.37^{*}$ \\
\hline & 17p13.1 & TP53(p53) & 1.40 & 1.19 & 1.18 \\
\hline & 17p12-17p11.2 & LLGL1 & 1.67 & 2.06 & $0.81^{*}$ \\
\hline & 17p12-17p11.2 & FLI, TOP3A & 1.60 & 1.88 & $0.85^{*}$ \\
\hline $18 q$ & $18 q 11.2$ & LAMA3 & 1.73 & 0.87 & $1.99 *$ \\
\hline \multirow[t]{2}{*}{$20 q$} & $20 q 13.1-q 13.2$ & PTPN1 & 1.46 & 1.43 & 1.02 \\
\hline & $20 q 13$ & TNFRSF6B(DCR3) & 1.50 & 1.23 & 1.22 \\
\hline \multirow[t]{3}{*}{$21 q$} & $21 q 22.3$ & RUNX1(AML1) & 1.40 & 1.16 & 1.21 \\
\hline & $21 q 22$ & DYRK1A & 1.37 & 1.13 & 1.21 \\
\hline & 21q tel & PCNT2(KEN) & 1.56 & 1.30 & 1.20 \\
\hline
\end{tabular}

${ }^{*} \mathrm{~m} / \mathrm{p}$ ratio: the ratio of DCNAs between the primary $(\mathrm{p})$ and metastatic $(\mathrm{m})$ tumor $(\geqq 1.30$ or $\leqq 0.85)$. No DCNAs of the loss ( $\left.\leqq 0.85\right)$ was detected in the metastasis.

(Figure 2). Especially, the loss of NRAS was mainly observed in 10 cases (76.9\%) of 13. NRAS mutations have detected prostate cancers before [9]. However, there has been no report about the relationship between bone tumors and NRAS.

The incidence of aggressive changes of bone tissue is low. Similar to other solid tumors, malignant changes are characterized by high propensity for metastasis. Metaphase CGH studies have identified frequent gains and amplifications at 1p21-32, 1q21-24, 5p13, 6p12, 8q23-24, 8cen-q13, 17p11.2-13, 19q, and $\mathrm{Xp} 21$, and frequent losses at 6q16, 10p12-pter, and 10q22-q26 in OS [2,10-13]. Recent studies have also reported that amplification at $17 \mathrm{p} 11.2$-ptel has been found in approximately $13-29 \%$ of high-grade OS $[11,14,15]$.

In our data, the most remarkable change in metastatic tumor was occurred at increases $(\geqq 1.30)$ of D1S1635 (1p36.22), D1S214 (1p36.31), EXT1 (8q24.11-q24), AFM137XA11 (9p11.2), CCND2 (12p13), 8 M16/SP6 (12ptel), IGH (D14S308), HIC1 (17p13.3), 282 M15/SP16 (17ptel), and LAMA3 (18q11.2). DCNAs of $p 53$ $(17 \mathrm{p} 13.1)$ have also increased scarcely $(1.19 \rightarrow 1.40)$, which have been suggested as an OS-related gene. As Chen, et al. [16] suggested, HIC1 (hypermethylated in cancer-1 located at $17 \mathrm{p} 13.3)$ was frequent with $p 53$ mutations in human OS. Their results indicated the importance of genes altered only through epigenetic 
mechanisms in cancer progression in conjunction with genetically modified tumor suppressor genes. In our study, HIC1 was also higher in the metastatic lesion than the primary site $(\mathrm{m} / \mathrm{p}$ ratio $=1.37$ in Table 2$)$. Therefore, we gave attention to the locus of $17 \mathrm{p} 13$ including $\mathrm{HIC1}$ as a target gene.

Recent studies have reported that overexpression of 17p11-p12 have been linked p53 degradation [10,16-20]. In Case \#13, the gain of LLGL1, FLI (TOP3A) at 17p11p12 have also detected. However, these two DCNAs were decreased in a metastatic sample, compared with primary tumor, which might be important in the step of metastasis. These findings support that target genes close to p53 (17p13.1), may contribute to OS tumorigenesis $[17,18]$.

Thus, the present pilot study suggests that array CGH could powerful means to detect genetic instability and gene aberrations that are reflected to the progression and outcome of primary aggressive bone tumors. HIC1 is increased at the both step of aggressive change and metastatic process. HIC1 might play a role of bone tumor progression and metastasis. We should pay attention the locus of 17p11-13 including HIC1, LLGL1, FLI (TOP3A), as well as $p 53$. Further detailed studies are necessary to clarify genetic pathways of the aggressive bone tumors.

\section{Conclusion}

Our results may provide several entry points for the identification of candidate genes associated with aggressive change of bone tumors. Especially, the locus 17p11-13 including HIC1 close to p53 was common high amplification in this series and review of the literature.

\section{Competing interests}

The authors declare that they have no competing interests.

\section{Authors' contributions}

MK participated in the data collection, performed the statistical analysis and drafted the manuscript.

AS, TY and TH made substantial contributions to the analysis and interpretation of data. KS helped to draft the manuscript. All authors read and approved the final manuscript.

\section{Acknowledgements}

This study was supported by grants from the he National Science Council of Japan (NSC 88-2314-B-075-096). The authors would like to thank Prof. Tomoatsu Kimura and Dr. Shigeharu Nogami, Department of Orthopaedics, University of Toyama, who provided clinical advices.

Received: 2 May 2012 Accepted: 25 June 2012

Published: 30 November 2012

\section{References}

1. Boehm AK, Neff JR, Squire JA, Bayani J, Nelson M, Bridge JA: Cytogenetic findings in 36 osteosarcoma specimens and a review of the literature. Pediatr Pathol Mol Med 2000, 19:359-376.

2. Sandberg AA, Bridge JA: Updates on the cytogenetics and molecular genetics of bone and soft tissue tumors: osteosarcoma and related tumors. Cancer Genet Cytogenet 2003, 145:1-30. 35-46.
3. Kallioniemi A, Kallioniemi OP, Sudar D, Rutovitz D, Gray JW, Waldman F, Pinkel D: Comparative genomic hybridization for molecular cytogenetic analysis of solid tumors. Science 1992, 258:818-821.

4. Pinkel D, Segraves R, Sudar D, Clark S, Poole I, Kowel D, Collins C, Kuo W-L, Chen C, Zhai Y, Dairkee SH, Ljung B, Gray JW, Albertson DG: High resolution analysis of DNA copy number variation using comparative genomic hybridization to microarrays. Nat Genet 1998, 20:207-211.

5. Pollack JR, Perou CM, Alizadeh AA, Eisen MB, Pergamenschikov A, Williams CF, Jeffrey SS, Bostein D, Brown PO: Genome-wide analysis of DNA copynumber changes using cDNA microarrays. Nat Genet 1999, 23:41-46.

6. Hashimoto K, Mori N, Tamesa T, Okada T, Kawauchi S, Oga T, Furuya T, Tangoku A, Oka M, Sasaki K: Analysis of DNA copy number aberrations in hepatitis $C$ virus-associated hepatocellular carcinomas by conventional CGH and array CGH. Mod Pathol 2004, 17:617-622.

7. Kanamori M: Cytogenetics of dedifferentiated chondrosarcoma. Toyama Med J 2007, 18:34-38.

8. Yasuda T, Kanamori M, Nogami S, Hori T, Oya T, Suzuki K, Kimura T: Establishment of a new human osteosarcoma cell line, UTOS-1: cytogenetic characterization by array comparative genomic hybridization. J Exp Clin Cancer Res 2009, 28:26-33.

9. Eskandarpour M, Hashemi J, Ringborg U, Platz A, Hansson J: Frequency of UV-inducible NRAS mutations in melanomas of patients with germline CDKN2A mutations. J Natl Cancer Inst 2003, 95:790-798.

10. Overholtzer M, Rao PH, Favis R, Lu X-Y, Elowitz MB, Barany F, Ladanyi M, Gorlick R, Levine AJ: The presence of p53 mutations in human osteosarcomas correlates with high levels of genomic instability. Proc Natl Acad Sci USA 2003, 100:11547-11552.

11. Tarkkanen M, Karhu R, Kallioniemi A, Elomaa I, Kivioja AH, Nevalainen J, Böhling T, Karaharju E, Hyytinen E, Knuutila S, Kallioniemi O-P: Gains and losses of DNA sequences in osteosarcomas by comparative genomic hybridization. Cancer Res 1995, 55:1334-1338.

12. Ozaki T, Schaefer K-L, Wai D, Buerger H, Flege S, Lindner N, Kevric M, Diallo R, Bankfalvi A, Brinkschmidt C, Juergens H, Winkelmann W, DockhornDworniczak B, Bielack SS, Poremba C: Genetic imbalances revealed by comparative genomic hybridization in osteosarcomas. Int J Cancer 2002, 102:355-365.

13. Ozaki T, Neumann T, Wai D, Schäfer $K-L$, van Valen $F$, Lindner $N$, Scheel $C$, Böcker W, Winkelmann W, Dockhorn-Dworniczak B, Horst J, Poremba C: Chromosomal alterations in osteosarcoma cell lines revealed by comparative genomic hybridization and multicolor karyotyping. Cancer Genetics Cytogenet 2003, 140:145-152.

14. Stock C, Kager L, Fink FM, Gadner H, Ambros PF: Chromosomal regions involved in the pathogenesis of osteosarcomas. Genes Chrom Cancer 2000, 28:329-336.

15. Zielenska M, Bayani J, Pandita A, Toledo S, Marrano P, Andrade J, Petrilli A, Thorner P, Sorenson P, Squire JA: Comparative genomic hybridization analysis identifies gains of 1 p35 approximately p36 and chromosome 19 in osteosarcoma. Cancer Genet Cytogenet 2001, 130:14-21.

16. Chen W, Cooper TK, Zahnow CA, Overholtzer M, Zhao Z, Ladanyi M, Karp JE, Gokgoz N, Wunder JS, Andrulis I, Levine AJ, Mankowski JL, Baylin SB: Epigenetic and genetic loss of Hic1 function accentuates the role of p53 in tumorigenesis. Cancer Cell 2004, 6:387-398.

17. van Dartel M, Cornelissen PWA, Redeker S, Tarkkanen M, Knuutila S, Hogendoorn PCW, Wsterveld A, Gomes I, Bras J, Hulsebos TJM: Amplification of 17p11.2-p12, including PMP22, TOP3A and MAPK7 in high-grade osteosarcoma. Cancer Genet Cytogenet 2002, 139:91-96.

18. van Dartel M, Redeker S, Bras J, Kool M, Hulsebos TJM: Overexpression through amplification of genes in chromosome region 17p11.2-p12 in high-grade osteosarcoma. Cancer Genet Cytogenet 2004, 152:8-14.

19. van Dartel M, Hulsebos TJM: Amplification and overexpression of genes in 17p11.2-p12 in osteosarcoma. Cancer Genet Cytogenet 2004, 153:77-80

20. Henriksen J, Aagesen TH, Maelandsmo GM, Lothe RA, Myklebost O, Forus A: Amplification and overexpression of COPS3 in osteosarcomas potentially target TP53 for proteasome-mediated degradation. Oncogene 2003, 22:5358-5361.

doi:10.1186/1756-9966-31-100

Cite this article as: Kanamori et al:: Array-based comparative genomic hybridization for genomic-wide screening of DNA copy number alterations in aggressive bone tumors. Journal of Experimental \& Clinical Cancer Research 2012 31:100. 